\title{
Modelling Growth Curves in a Nondescript Italian Chicken Breed: an Opportunity to Improve Genetic and Feeding Strategies
}

\author{
Maria Selvaggi, Vito Laudadio, Cataldo Dario and Vincenzo Tufarelli \\ Department DETO, Section of Veterinary Science and Animal Production, \\ University of Bari 'Aldo Moro', 70010 Valenzano (BA), Italy
}

\begin{abstract}
Growth, known as the relation between liveweight and age, is explained mathematically by functions that have parameters with biological meaning. These parameters are used to describe growth pattern over time and to estimate the expected weight of animals at specific ages. Animal growth generally follows a sigmoidal pattern and several nonlinear functions have been used to describe it. This study was carried out to estimate the parameters of logistic, Gompertz and Richards growth curve models in a nondescript chicken breed population from southern Italy to determine the goodness of fit. Male and female birds were weighed weekly starting from two to twenty-four weeks of age. Based on our dataset, chickens showed a slow-growth pattern. All the growth functions evaluated were easily fitted to the observed data by nonlinear regression; our findings showed that Gompertz model fitted liveweight data very well both for male and female birds being the best model for studying the growth of our animals. Nevertheless, the four-parameter Richards function provided also a good fit of the data. Success in studying the growth characteristics of our nondescript chicken breed will contribute to define appropriate feeding regimens and to develop selection programme.
\end{abstract}

Key words: chicken breed, growth curve, nonlinear model

\section{Introduction}

Growth is a traits of economic importance in poultry production and it is influenced by genetics and environmental effects. It is possible to define growth as an increase in body size per unit time or as the relationship between lifetime weight and age (Lawrence and Fowler, 2002). Growth is a continuous function during the animal's life, from embryonic stages up to adult age and it is mathematically explained by growth models that have parameters with biological meaning (Fitzhugh, 1976). These parameters are used to describe growth over time and to estimate the expected weight of individuals at specific age (Yakupoglu and Atil, 2001). That being so, it is possible to use mathematical models to identify better strategies to improve livestock production also estimating daily nutrient requirements of animals at different ages and belonging to various genetic groups (Pomar et al., 2009). Moreover, growth curve parameters are highly heritable and widely used in selection studies (Grossman and Bohren, 1985; Mignon-Grasteau et al., 2000). Animal growth

Received: March 20, 2015, Accepted: May 14, 2015

Released Online Advance Publication: June 25, 2015

Correspondence: Prof. C. Dario, Department DETO, Section of Veterinary

Science and Animal Production, University of Bari 'Aldo Moro', 70010

Valenzano (BA), Italy. (E-mail: cataldo.dario@uniba.it) generally follows a sigmoidal pattern; a great number of nonlinear functions have been used to describe growth in mammals, avian species and fish (Parks, 1982; France et al., 1996). The commonly used nonlinear growth models are Gompertz, Richards, Logistic, Brody, Bertalanffy and Weibull (Koops, 1986).

Growth curves for poultry generally have the following characteristics: an accelerating phase of growth from hatching, a point of inflection in the growth curve at which the growth rate is maximum, a phase where growth rate is decelerating, and a limiting value (asymptote) mature weight (Wilson, 1977). The logistic equation can be derived by assuming that the quantity of growth is proportional to body weight; growth increases at a rate that is proportional to the amount of nutrients and considering that growth is irreversible. The assumptions underlying Gompertz equation are that the growth is proportional to body weight and that growth rate decays exponentially with time (Thornley and France, 2007). Richards equation is a four-parameter model based on a more empirical construct with a shape parameter of a non clear biological meaning. The reason why Richards model is attractive for growth curve modelling is its variable point of inflection in proportion to asymptotic weight: both logistic and Gompertz functions have a fixed flexible point at 50.0 and $36.8 \%$ of the asymptotic weight, respectively 
(Ahmadi and Mottaghitalab, 2007).

The Gompertz growth model has been cited as the model of choice for chicken data based on its overall fit and its biological meaning of curve parameters (Rickefels, 1985; Anthony et al., 1991; Mignon-Grasteau et al., 1999; Aggrey, 2002). However, to our best knowledge no studies were conducted on growth curve modelling in the present chicken population. Therefore, the aim of the present study was to compare three nonlinear models (logistic, Gompertz, Richards) in order to describe the growth of a nondescript chicken breed from southern Italy. We hypothesize to observe a sigmoidal growth pattern and we are looking for the most appropriate curve among those studied. Moreover, we expect to observe some differences between male and female birds growth patterns.

\section{Materials and Methods}

\section{Birds and Environmental Conditions}

This study was conducted in the experimental poultry facilities located at the University of Bari 'Aldo Moro', Italy. A total of one hundred and four chickens (58 females and 46 males) were used. Birds were divided into two groups based on sex and were housed in different indoor pens $\left(0.15 \mathrm{~m}^{2}\right.$ /bird) equipped with feeders and drinkers, with free access to open air runs $\left(3 \mathrm{~m}^{2} /\right.$ bird) without grass. For the first two weeks of life, the chickens were free-range reared and fed common starter corn-soybean based diet. Then, birds were fed a basal mash corn-soybean diet containing $14.5 \%$ crude protein and $11.7 \mathrm{MJ}$ of metabolizable energy (ME) per $\mathrm{kg}$ of diet (Table 1), designed to meet or exceed the nutrient requirements for chickens (NRC, 1994). The ME of the diet was estimated using the Carpenter and Clegg equation (Leeson and Summers, 2001). Feed and water were provided ad libitum throughout the entire trial. Weekly body weight (BW) records, from two to twenty-four weeks of age, were collected and used for the study. Average BW at first check were 165.56 and $183.92 \mathrm{~g}$ for females and males, respectively. The most precocious birds reached sexual maturity at twenty-one weeks of age, nevertheless all the animals attained sexual maturity and the females started laying within twenty-four weeks of age.

\section{Statistical Analysis}

The growth functions used in this investigation were logistic, Gompertz and Richards as follow:

$$
\begin{aligned}
& \text { Logistic } \\
& \mathrm{W}(\mathrm{t})=\mathrm{A} *(1+\mathrm{B} * \exp (-\mathrm{k} * \mathrm{t}))^{-1} \\
& \text { Gompertz } \\
& \mathrm{W}(\mathrm{t})=\mathrm{A} * \exp (-\mathrm{B} * \exp (-\mathrm{k} * \mathrm{t})) \\
& \text { Richards } \\
& \mathrm{W}(\mathrm{t})=\mathrm{A} *\left(1+\mathrm{B} * \exp \left(-\mathrm{k}^{*} \mathrm{t}\right)\right)^{-1 / d}
\end{aligned}
$$

where $\mathrm{W}(\mathrm{t})$ is the body weight $(\mathrm{g})$ of birds at $\mathrm{t}$ weeks of age and $\mathrm{A}, \mathrm{B}, \mathrm{k}$ are model parameters. In particular, $\mathrm{A}$ is the

\begin{tabular}{|c|c|}
\hline \multicolumn{2}{|c|}{ Ingredients, $\mathrm{g} / \mathrm{kg}$ as-fed basis } \\
\hline Corn & 658.7 \\
\hline Soybean meal ( $48 \% \mathrm{CP})$ & 190.0 \\
\hline Calcium carbonate & 42.1 \\
\hline Oyster shell & 30.7 \\
\hline Wheat bran & 29.5 \\
\hline Wheat & 21.8 \\
\hline Dicalcium phosphate & 13.3 \\
\hline Vitamin-mineral premix ${ }^{1}$ & 6.0 \\
\hline Sodium chloride & 2.5 \\
\hline Soybean oil & 2.0 \\
\hline Sodium bicarbonate & 1.2 \\
\hline Choline chloride & 1.0 \\
\hline DL-Met & 0.7 \\
\hline L-Lys & 0.5 \\
\hline \multicolumn{2}{|l|}{ Chemical analysis, $\%$} \\
\hline Dry matter & 89.70 \\
\hline Crude protein & 14.50 \\
\hline Crude fat & 2.55 \\
\hline Ash & 5.89 \\
\hline \multicolumn{2}{|l|}{ Calculated analysis } \\
\hline $\mathrm{ME}(\mathrm{MJ} / \mathrm{kg}$ of diet) & 11.7 \\
\hline Lys, \% & 0.95 \\
\hline Calcium, \% & 3.00 \\
\hline Met + Cys, \% & 0.58 \\
\hline Available P, \% & 0.35 \\
\hline
\end{tabular}
asymptotic weight when time goes to infinity; B is a scaling parameters (constant of integration) related with initial values of weight, $\mathrm{k}$ is the maturing rate and $\mathrm{d}$ is the shape parameter.

Weight and age at the point of inflection were calculated

\footnotetext{
${ }^{1}$ Supplied per kg of feed: vitamin A 11,000 IU; vitamin $\mathrm{D}_{3}$ 3,500 IU; vitamin E $100 \mathrm{IU}$; vitamin $\mathrm{K}_{3} 5 \mathrm{mg}$; vitamin $\mathrm{B}_{12}$ $0.03 \mathrm{mg}$; riboflavin, $12 \mathrm{mg}$; nicotinic acid $55 \mathrm{mg}$; pantothenic acid $15 \mathrm{mg}$; folic acid $2 \mathrm{mg}$; pyridoxine $6 \mathrm{mg}$; thiamine $3 \mathrm{mg}$; d-biotin $0.3 \mathrm{mg}$; choline $300 \mathrm{mg}$; $\mathrm{Cu} 10 \mathrm{mg}$; I 2 $\mathrm{mg}$; Fe $50 \mathrm{mg}$; Mg $120 \mathrm{mg}$; Zn $100 \mathrm{mg}$; Se $0.3 \mathrm{mg}$.
}

as: $\mathrm{W}_{\mathrm{i}}=\mathrm{A} / 2$ and $\mathrm{t}_{\mathrm{i}}=\ln (\mathrm{B}) / \mathrm{k}$ for logistic; $\mathrm{W}_{\mathrm{i}}=\mathrm{A} / \mathrm{e}$ and $\mathrm{t}_{\mathrm{i}}=\ln$ (B) $/ \mathrm{k}$ for Gompertz and $\mathrm{W}_{\mathrm{i}}=\mathrm{A} /(\mathrm{d}+1)^{1 / \mathrm{d}}$ and $\mathrm{t}_{\mathrm{i}}=-1 / \mathrm{k}^{*} \ln \mid \mathrm{d} /$ B| for Richards.

The models were fitted to the data using the NLIN procedure of SAS statistical package program (Sas/Stat User's Guide Statistics, 1999).

Root mean square error (RMSE), coefficient of determination $\left(\mathrm{R}^{2}\right)$, adjusted $\mathrm{R}^{2}\left(\operatorname{adj} \mathrm{R}^{2}\right)$ and Akaike Information Criterion (AIC) were used to assess the goodness of fit of each model as follow:

$\mathrm{RMSE}=\operatorname{sqrt}(\mathrm{SSE} /(\mathrm{n}-\mathrm{k})) ; \mathrm{R}^{2}=1-(\mathrm{SSE} / \mathrm{SST}) ; \operatorname{adjR}^{2}=\mathrm{R}^{2}$ $-\left(\left(1-\mathrm{R}^{2}\right)^{*}(\mathrm{k} /(\mathrm{n}-\mathrm{k}-1))\right) ; \mathrm{AIC}=\mathrm{n} \ln (\mathrm{SSE} / \mathrm{m})+2 \mathrm{k}$; where $\mathrm{SSE}=$ sum of square of errors; $\mathrm{SST}=$ total sum of squares; $\mathrm{n}=$ number of observations; $\mathrm{k}=$ number of parameters.

By using the six obtained equations, the predicted growth curves were then plotted for females and males respectively and presented with observed liveweight data.

\section{Results}

In Table 2 the growth curve parameters, the calculated inflection points traits and the goodness of fit criteria for the 
Table 2. Growth curve parameters, inflection point traits and calculated goodness of fit criteria

\begin{tabular}{|c|c|c|}
\hline & Female & Male \\
\hline \multicolumn{3}{|l|}{ Logistic } \\
\hline Asymptotic weight (A) & 4839.8561 & 5000.2655 \\
\hline Constant of integration (B) & 31.5254 & 30.9128 \\
\hline Maturing rate $(\mathrm{k})$ & 0.2581 & 0.2558 \\
\hline Weight at the inflection point $\left(\mathrm{W}_{\mathrm{i}}\right), \mathrm{g}$ & 2419.93 & 2500.13 \\
\hline Age at the inflection point $\left(t_{i}\right)$, wk & 13.3670 & 13.4135 \\
\hline RMSE & 81.3210 & 80.5895 \\
\hline $\mathrm{R}^{2}$ & 0.99718 & 0.99738 \\
\hline Adjusted $\mathrm{R}^{2}$ & 0.99674 & 0.99696 \\
\hline Akaike Information Criterion (AIC) & 340.3266 & 339.9109 \\
\hline \multicolumn{3}{|l|}{ Gompertz } \\
\hline Asymptotic weight (A) & 5661.5816 & 5870.0393 \\
\hline Constant of integration (B) & 5.2024 & 5.1379 \\
\hline Maturing rate $(\mathrm{k})$ & 0.1369 & 0.1352 \\
\hline Weight at the inflection point $\left(\mathrm{W}_{\mathrm{i}}\right), \mathrm{g}$ & 2082.78 & 2159.47 \\
\hline Age at the inflection point $\left(\mathrm{t}_{\mathrm{i}}\right)$, wk & 12.0462 & 12.1054 \\
\hline RMSE & 45.6000 & 43.8128 \\
\hline $\mathrm{R}^{2}$ & 0.99912 & 0.99923 \\
\hline Adjusted $\mathrm{R}^{2}$ & 0.99898 & 0.99910 \\
\hline Akaike Information Criterion (AIC) & 313.7158 & 311.8766 \\
\hline \multicolumn{3}{|l|}{ Richards } \\
\hline Asymptotic weight (A) & 5518.6517 & 5700.2573 \\
\hline Constant of integration (B) & 0.5820 & 0.6604 \\
\hline Maturing rate $(\mathrm{k})$ & 0.1487 & 0.1484 \\
\hline Shape parameter (d) & 0.0948 & 0.1073 \\
\hline Weight at the inflection point $\left(\mathrm{W}_{\mathrm{i}}\right), \mathrm{g}$ & 2122.83 & 2204.72 \\
\hline Age at the inflection point $\left(t_{i}\right)$, wk & 12.2060 & 12.2854 \\
\hline RMSE & 44.7289 & 42.5921 \\
\hline $\mathrm{R}^{2}$ & 0.99914 & 0.99922 \\
\hline Adjusted $\mathrm{R}^{2}$ & 0.99895 & 0.99905 \\
\hline Akaike Information Criterion (AIC) & 358.8285 & 356.5767 \\
\hline
\end{tabular}

RMSE, root mean square error

logistic, Gompertz and Richards equations are reported. The results indicated that all the growth functions were easily fitted to the observed data by nonlinear regression. The Figures 1 and 2 show the estimated growth curve patterns in comparison to the measured liveweights for female and male birds, respectively.

\section{Female Growth Modelling}

The models comparison based on the coefficient of determination $\left(\mathrm{R}^{2}\right)$ showed that Gompertz and Richards models led to an improved fit of data compared to logistic equation (0.99912 and 0.99914 vs. 0.99718, respectively). A similar trend was observed for the $\mathrm{Adj}^{2}$. Moreover, to deeply evaluate the best fit it will be necessary to consider the RMSE and the AIC values. In particular, the smaller the RMSE value, the more reliably the equation fits the data; that being so, both Richards and Gompertz functions has the best fitting. Anyway, when it considers the Akaike Information Criterion, the function with the lowest value is deemed to be the most suitable. When the functions ranked based on AIC, the Gompertz model showed the smaller value followed by logistic and Richards models. To support these findings, Fig. 1 illustrates the comparison between experimental data and estimated growth curves and it is possible to observe that Gompertz and Richards models described the growth pattern of female birds very well; on the other hand the logistic model slightly overestimates the initial body weight and underestimates the final body weight.

\section{Male Growth Modelling}

Based on $\mathrm{R}^{2}$ and $A d j \mathrm{R}^{2}$, the results indicated that Gompertz and Richards functions provide the best fit to the data. The highest value for RMSE was obtained for logistic model indicating lack of fit; RMSE values calculated for Gompertz and Richards functions were similar and smaller (80.5895 vs. 43.8128 and 42.5921). Furthermore, fitting the growth equations led to the lowest AIC for Gompertz, followed by logistic and Richards models. As per female chickens, the logistic model slightly overestimates the initial body weight and underestimates the final body weight; the Gompertz and 

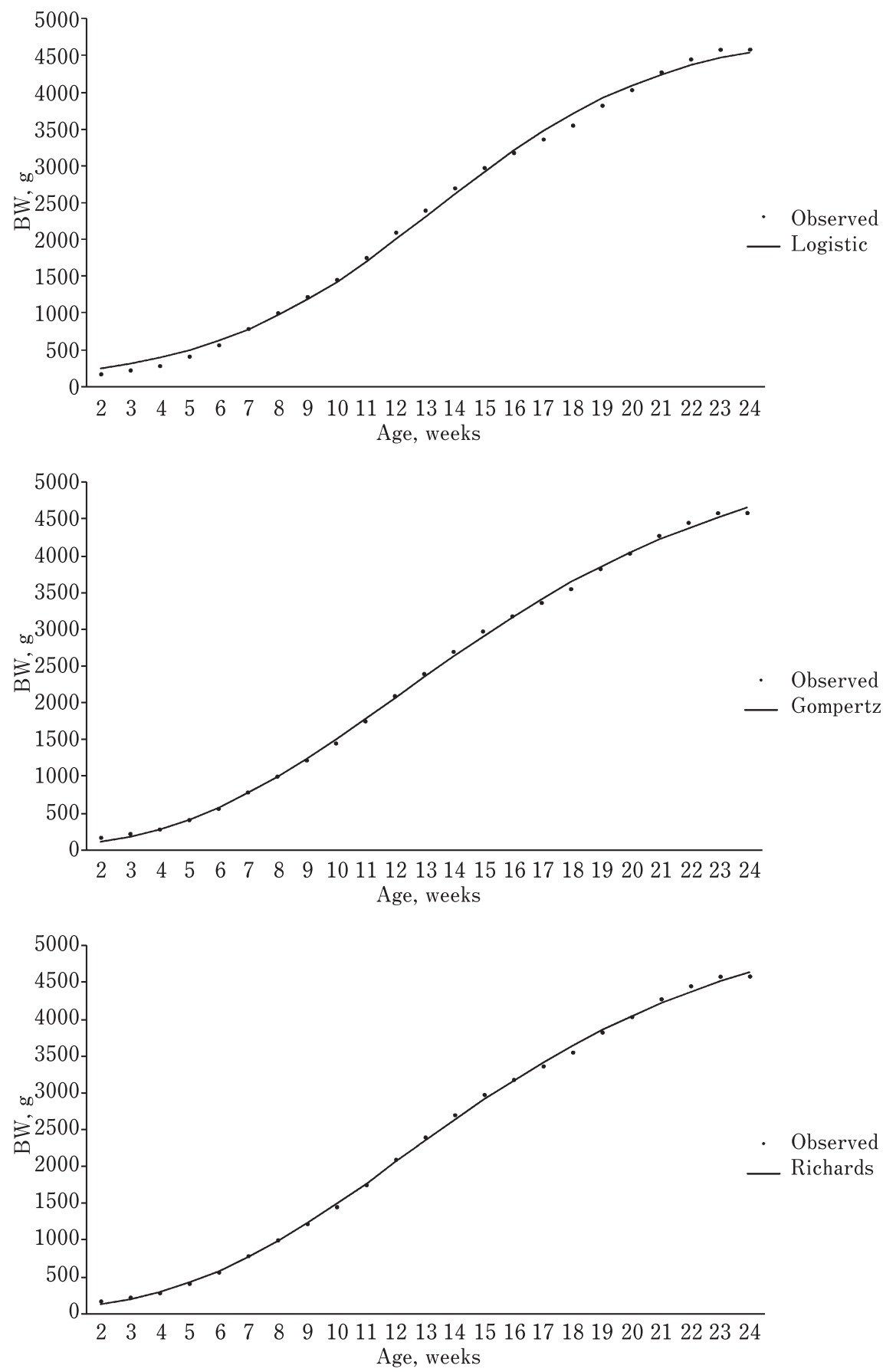

Fig. 1. Growth curves of female birds according to logistic, Gompertz and Richards models in comparison to the observed data.

Richards functions explained the growth of male birds in a reliable way, as illustrated in Fig. 2.

\section{Inflection Point Traits}

The estimate of weight and age at the inflection point are reported in Table 2. Age at the inflection point $\left(\mathrm{t}_{\mathrm{i}}\right)$ is the maximum growth rate longitudinal time frame of liveweight. Differently to the values of $t_{i}$ estimated using logistic model
(13.3670 and $13.4135 \mathrm{wk}$ for female and male chickens, respectively) those calculated using Richards and Gompertz equations were smaller for both sexes. The highest $\mathrm{W}_{\mathrm{i}}$ was found by using logistic function, followed by Richards and Gompertz, both in male and female birds. Weight at the inflection point and asymptotic weight of males were higher than females. 

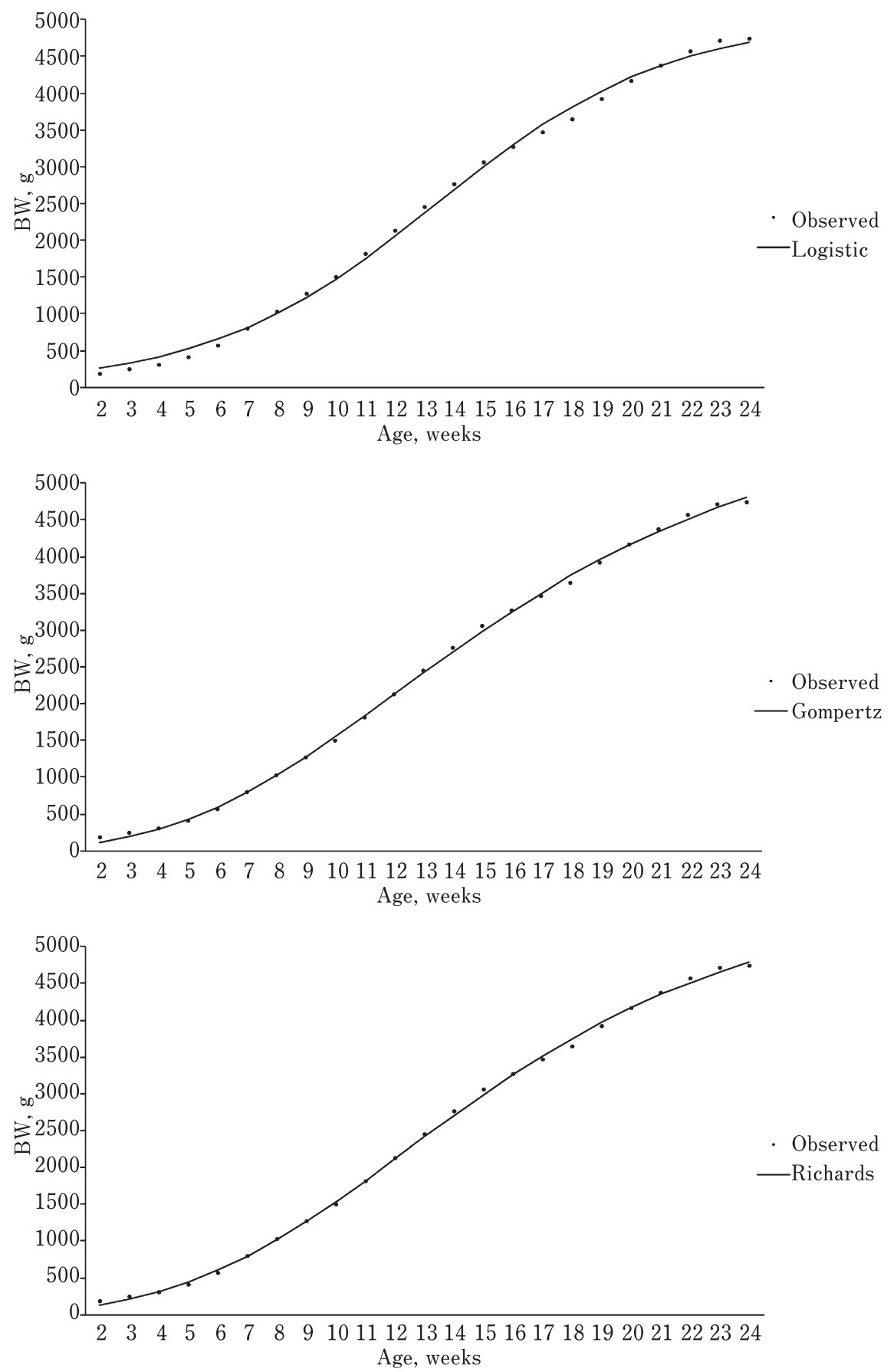

Fig. 2. Growth curves of male birds according to logistic, Gompertz and Richards models in comparison to the observed data.

\section{Discussion}

Our findings showed that Gompertz model fitted liveweight data very well both for male and female birds being the best model for studying the growth of our animals. Moreover, it is necessary to consider that Gompertz equation requires only three parameters when compared to the four- parameters Richards function. Nevertheless, the fourparameter Richards function provided also a good fit of the data, followed by the logistic equation. To date, the available literature on this regards have shown contrasting results. In general, the nonlinear equations fitted growth data better than the linear model. Some authors reported the appropriateness of Gompertz curve to describe the growth of poultry 
(Mignon-Grasteau et al., 2000; 2001; Aggrey, 2002; Roush et al., 2006; Norris et al., 2007, Rizzi et al., 2013); others reported the superiority of Richards model (Goliomytis et al., 2003; Zhang et al., 2008; Osei-Amponsah et al., 2014), and others suggested the correctness of Bertalanffy equation (Yang et al., 2006). All these differences may be due to a great number of reasons: breed or population structure, sex of birds, feeding management, environmental conditions, sampling and statistical methods.

Considering the growth parameters and thus the growth pattern of the analyzed population, these traits are similar to those observed in other slow-growing chicken breeds. In particular, the asymptotic weights estimated in the present study were closer to the values reported by other authors in slow-growing populations (Wang and Zuidhof, 2004; Eleroğlu et al., 2014) but higher if compared to those obtained from local genotypes and commercial hybrids (Aggrey, 2002; Atil et al., 2007; Norris et al., 2007; Ahmadi and Golian, 2008; Rizzi et al., 2013). The range of $t_{i}$ values estimated in the present investigation varies from 12.046 to 13.414 weeks of age being similar to as reported by Eleroğlu et al. (2014), by Osei-Amponsah et al. (2014) in Ghanaian local chickens and by Rizzi et al. (2013) in Italian local chicken populations and Yang et al. (2006) in Jinghai yellow chickens. However, most of the available literature reports a very low age at inflection point, irrespective of the growth model fitted due to the fast growing pattern frequently observed in chickens (Knížetová et al., 1985; Goliomytis et al, 2003; Santos et al., 2005; Sakomura et al., 2011). Male chickens showed higher values than females in terms of $\mathrm{W}_{\mathrm{i}}$ and this result was found to be in agreement with findings reported by other authors (Santos et al., 2005; Rizzi et al., 2013; Eleroğlu et al., 2014).

Success in studying the growth characteristics of our nondescript chicken breed will contribute to define more appropriate feeding regimens to cover the high nutritional requirements during the growth phase from hatch until the age at the inflection point; moreover, sex separating feeding could be a viable strategy. Furthermore, to select the best function based on its ability to describe relationship between liveweight and age is the first step to develop breeding programme. The growth curve parameters will provide an opportunity to design selection strategies by modifying feeding practices or genetic makeup of the growth curve shape. The growth parameters estimated by Gompertz function could be included in genetic improvement programme: as previously reported by Barbato (1991) and Mignon-Grasteau et al. (1999) these parameters showed medium-high values of heritability. That being so, it will be mandatory to estimate the heritability of growth curve parameters and the phenotypic-genetic correlations.

To rescue local populations could increase poultry biodiversity. Moreover, to study small populations that are at risk of going extinct may contribute to add knowledge on their performances and to safeguard these populations that are often reared as "backyards chickens". This intent may be of great importance also considering that the demand for organic and free-range productions is increasing (Sossidou et al., 2011; Thiruvenkadan et al., 2011). The slow-growing pattern of the investigated chickens suggests their potential use for organic and alternative production systems to avoid the economic losses occurring with the production of fastgrowing hybrids under condition wherein there is no control of environmental factors.

\section{References}

Aggrey SE. Comparison of three nonlinear and spline regression models for describing chicken growth curves. Poultry Science, 81: 1782-1788. 2002.

Ahmadi H and Golian A. Non-linear hyperbolastic growth models for describing growth curve in classical strain of broiler chickens. Research Journal of Biological Science, 3: 13001304. 2008.

Ahmadi $\mathrm{H}$ and Mottaghitalab M. Hyperbolastic models as a new powerful tool to describe broiler growth kinetics. Poultry Science, 86: 2461-2465. 2007.

Anthony NB, Emmerson DA, Nestor KE, Bacon WL, Sigel P and Dunnington EA. Comparison of growth curves of weight selected populations of turkeys, quail, and chickens. Poultry Science, 70: 13-19. 1991.

Atil H, Grossman M and Takma C. Comparison of growth curve models on average and individual body weights in chickens. Archiv Fur Geflugelkunde, 71: 1-5. 2007.

Barbato GF. Genetic architecture of growth curve parameters in chickens. Theoretical Applied Genetics, 83: 24-32. 1991.

Eleroğlu H, Yıldırım A, Şekeroğlu A, Çoksöyler FN and Duman M. Comparison of growth curves by growth models in slowgrowing chicken genotypes raised the organic system. International Journal of Agriculture and Biology, 16: 529-535. 2014.

Fitzhugh HA. Analysis of growth curves and strategies for altering their shape. Journal of Animal Science, 42: 1036-1051. 1976.

France J, Dijkstra J and Dhanoa MS. Growth functions and their application in animal sciences. Annales Zootechnie, 45: 165174. 1996.

Goliomytis M, Panopoulou E and Rogdakis E. Growth curves for body weight and major component parts, feed consumption, and mortality of male broiler chickens raised to maturity. Poultry Science, 82: 1061-1068. 2003.

Grossman M and Bohren BB. Logistic growth curve of chickens: heritability of parameters. Journal of Heredity, 76: 459-462. 1985.

Knížetová H, Hyanek J, Hájková H, Kníže B and ŠIler R. Growth curves of chickens with different type of performance. Journal of Animal Breeding and Genetics, 102: 256-270. 1985.

Koops WJ. Multiphasic growth curve analysis. Growth, 50: 169177. 1986

Lawrence TLJ and Fowler VR. Growth of farm animals. $2^{\text {nd }}$ ed. CAB International, Wallingford, UK. 2002.

Leeson S and Summers JD. Nutrition of the Chicken. University Books, Guelph. 2001.

Mignon-Grasteau S, Beaumont C, Le Bihan-Duval E, Poivey JP, De Rochambeau H and Ricard FH. Genetic parameters of growth curve parameters in male and female chickens. British Poultry Science, 40: 44-51. 1999.

Mignon-Grasteau S, Piles M, Varona L, De Rochambeau H, Poivey JP, Blasco A and Beaumont C. Genetic analysis of growth curve parameters for male and female chickens resulting from 
selection on shape of growth curve. Journal of Animal Science, 78: 2515-2524. 2000.

Mignon-Grasteau S, Beaumont C and Ricard FH. Genetic analysis of a selection experiment on the growth curve of chickens. Poultry Science, 80: 849-854. 2001.

National Research Council. Nutrient Requirements for Poultry. 9th rev. ed. National Academy Press, Washington, DC. 1994.

Norris D, Ngambi JW, Benyi K, Makgahlela ML, Shimelis HA and Nesamvuni EA. Analysis of growth curves of indigenous male Venda and Naked Neck chickens. South African Journal of Animal Science, 37: 21-26. 2007.

Osei-Amponsah R, Kayang BB, Naazie A, Barchia IM and Arthur PF. Evaluation of models to describe temporal growth in local chickens of Ghana. Iranian Journal of Applied Animal Science, 4: 855-861. 2014.

Parks JR. A Theory of Feeding and Growth of Animals. SpringerVerlag, Berlin. 1982.

Pomar C, Hauschild L, Zhang GH, Pomar J and Lovatto PA. Applying precision feeding techniques in growing-finishing pig operations. Revista Brasileira de Zootecnia, 38: 226-237. 2009.

Ricklefs RE. Modification of growth and development of muscles of poultry. Poultry Science, 64: 1563-1576. 1985.

Rizzi C, Contiero B and Cassandro M. Growth patterns of Italian local chicken populations. Poultry Science, 92: 2226-2235. 2013.

Roush WB, Dozier WA and Branton SL. Comparison of Gompertz and neural network models of broiler growth. Poultry Science, 85: 794-797. 2006.

Sakomura NK, Gous RM, Marcato SM and Fernandes JBK. A description of the growth of the major body components of 2 broiler chicken strains. Poultry Science, 90: 2888-2896. 2011.
Santos AL, Sakomura NK, Freitas ER, Fortes CMS and Carrilho ENVM. Comparison of free range broiler chicken strains raised in confined or semi-confined systems. Revista Brasileira de Ciência Avícola, 7: 85-92. 2005.

SAS User's Guide Statistics, Version 8.0 Edition SAS Inst. Inc. Cary, NC. 1999.

Sossidou EN, Dal Bosco A, Elson HA and Fontes CMGA. Pasturebased systems for poultry production: implications and perspectives. World's Poultry Science Journal, 67: 47-58. 2011.

Thiruvenkadan AK, Prabakaran R and Panneerselvam S. Broiler breeding strategies over the decades: an overview. World's Poultry Science Journal, 67: 309-336. 2011.

Thornley JHM and France J. Mathematical Models in Agriculture: Quantitative Methods for the Plant, Animal and Ecological Sciences. 2nd ed. CABI Publishing, Wallingford, UK. 2007.

Wang $\mathrm{Z}$ and Zuidhof MJ. Estimation of growth parameters using a nonlinear mixed Gompertz model. Poultry Science, 83: 847852. 2004.

Wilson BJ. Growth curves: their analysis and use. In: Production (Boorman KN and Wilson BJ eds.), pp: 89-115. British Poultry Science Ltd. Edinburgh, UK. 1977.

Yakupoglu Ç and Atil H. Comparison of growth curve models on broilers II. Comparison of models. Online Journal of Biological Science, 1: 682-684. 2001.

Yang Y, Mekki DM, Lv SJ, Wang LY, Yu JH and Wang JY. Analysis of fitting growth models in Jinghai mixed-sex yellow chicken. International Journal of Poultry Science, 5: 517-521. 2006.

Zhang H, Wu C, Chamba Y, Ling Y and Ji S. Influences of altitude on growth curves in Tibetan chicken and its hybrid. Frontiers of Agriculture in China, 2: 237-241. 2008. 